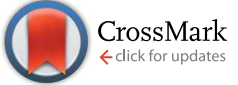

Cite this: Chem. Sci., 2015, 6, 6806

\title{
Pushing NMR sensitivity limits using dynamic nuclear polarization with closed-loop cryogenic helium sample spinning
}

\author{
E. Bouleau, ${ }^{a b}$ P. Saint-Bonnet, ${ }^{a b}$ F. Mentink-Vigier, ${ }^{a b}$ H. Takahashi, ${ }^{a b}{ }^{a b}$ J.F. Jacquot, ${ }^{a b}$ \\ M. Bardet, ${ }^{\text {ab }}$ F. Aussenac, ${ }^{c}$ A. Purea, ${ }^{d}$ F. Engelke, ${ }^{d}$ S. Hediger, ${ }^{\text {abe }}$ D. Lee ${ }^{\text {ab }}$ and G. De \\ Paëpe ${ }^{\star a b}$
}

\begin{abstract}
We report a strategy to push the limits of solid-state NMR sensitivity far beyond its current state-of-the-art. The approach relies on the use of dynamic nuclear polarization and demonstrates unprecedented DNP enhancement factors for experiments performed at sample temperatures much lower than $100 \mathrm{~K}$, and can translate into 6 orders of magnitude of experimental time-savings. This leap-forward was made possible thanks to the employment of cryogenic helium as the gas to power magic angle sample spinning (MAS) for dynamic nuclear polarization (DNP) enhanced NMR experiments. These experimental conditions far exceed what is currently possible and allows currently reaching sample temperatures down to $30 \mathrm{~K}$ while conducting experiments with improved resolution (thanks to faster spinning frequencies, up to $25 \mathrm{kHz}$ ) and highly polarized nuclear spins. The impressive associated gains were used to hyperpolarize the surface of an industrial catalyst as well as to hyperpolarize organic nano-assemblies (self-assembling peptides in our case), for whom structures cannot be solved using diffraction techniques. Sustainable cryogenic helium sample spinning significantly enlarges the realm and possibilities of the MAS-DNP technique and is the route to transform NMR into a versatile but also sensitive atomic-level characterization tool.
\end{abstract}

Received 31st July 2015

Accepted 26th August 2015

DOI: $10.1039 / \mathrm{c} 5 \mathrm{sc} 02819 a$

www.rsc.org/chemicalscience

\section{Introduction}

Solid-state nuclear magnetic resonance (ssNMR) is an indispensable tool for biological, chemical, and physical analysis. However, one important weakness of the technique is its lack of sensitivity, with some experiments lasting weeks and others being completely infeasible. Nevertheless, recent technological advancements pioneered by Griffin and co-workers, ${ }^{1}$ which have now been commercialized, ${ }^{2}$ have permitted huge sensitivity gains by combining high magnetic fields, sample rotation at the so-called magic angle, and dynamic nuclear polarization (DNP). ${ }^{3-6}$ DNP involves the microwave-driven transfer of the substantial spin polarization of unpaired electrons to nuclear spins, increasing nuclear polarization (and thus NMR sensitivity), and reducing experimental times by many orders of magnitude. The current state-of-the-art technology for DNPenhanced ssNMR allows experiments to be performed at a

${ }^{a}$ Univ. Grenoble Alpes, INAC, F-38000 Grenoble, France. E-mail: gael.depaepe@cea.fr ${ }^{b} C E A$, INAC, F-38000 Grenoble, France

'Bruker BioSpin SAS, Wissembourg, France

${ }^{d}$ Bruker BioSpin GmbH, Rheinstetten, Germany

${ }^{e} C N R S$, SCIB, F-38000 Grenoble, France

$\dagger$ Present address: ETH Zurich, Department of Physics, CH-8093 Zurich, Switzerland. temperature of $\sim 100 \mathrm{~K}$, with magic angle spinning (MAS) frequencies up to $15 \mathrm{kHz}$ for a $3.2 \mathrm{~mm}$ diameter rotor, using cold nitrogen gas to both cool the sample and pneumatically spin it to the desired rotation frequency. ${ }^{2}$

Despite the very large success of MAS-DNP, there are still significant improvements that can be made to push further the limits of sensitivity. One of the current limitations of the approach is the use of cold nitrogen gas to power the pneumatic rotation of the turbine. This prevents working temperatures below $100 \mathrm{~K}$, which would be required to avoid the use of expensive high-power, high-frequency microwave $(\mu \mathrm{w})$ sources (e.g. gyrotrons). In addition, the fluidic properties of cold nitrogen strongly limit the maximum sample spinning frequency as compared to room temperature nitrogen gas. To overcome these limitations, helium (He) presents itself as a highly pertinent gas for MAS at or below $100 \mathrm{~K}$ due to its fluidic properties, ${ }^{7}$ with the speed of sound in He being much higher than in nitrogen $\left(\mathrm{N}_{2}\right)$ gas. However, it was up to now not clear that fast and stable spinning could be achieved at such temperatures without significant modifications of the rotor/ stator design. ${ }^{8-10}$ So far, only moderate sample spinning was demonstrated using pressurized helium tanks. ${ }^{\mathbf{8} 11-13}$ In addition, in He gas close to ambient pressure, the critical electric rf-field strength for voltage breakthrough is relatively low and may lead to arcing, a well-known issue in NMR probe operation at cold 
helium temperatures. Moreover, cooling to cryogenic temperatures the high flows of He gas needed for both cooling and pneumatic spinning the sample rotor is a technological challenge, especially considering the cost and sustainability of He. ${ }^{14}$ For these reasons, some designs for "ultra-low" temperature MAS (ULT-MAS) employ $\mathrm{N}_{2}$ gas for spinning the sample and $\mathrm{He}$ gas for cooling. ${ }^{15,16}$ Nevertheless, this requires a separation of the two gases so that $\mathrm{N}_{2}$ is not liquefied or even solidified during sample rotation. This elegant approach has been demonstrated to work for large and elongated $4 \mathrm{~mm}$ rotors. ${ }^{15,16}$

In this work we demonstrate an alternative route whereby the use of cryogenic helium gas enables reaching much faster MAS rates and much lower temperatures, the latter increasing significantly the hyperpolarization efficiency of the cross-effect (CE) MAS-DNP mechanism ${ }^{\mathbf{1 7}, 18}$ as compared to $100 \mathrm{~K}$ measurements. These results, obtained using a magnetic field strength of $10 \mathrm{~T}$, are of primary importance for the development of MASDNP at higher magnetic fields and should allow extending significantly the range of polarizing agents that can be employed efficiently (biradicals, ${ }^{19-21}$ organic radicals with narrow EPR resonances, ${ }^{22}$ metal ions ${ }^{23}$ intrinsic paramagnetic defects $^{24}$ etc.). This is of course of direct relevance for the study of systems with extremely low sensitivity and/or those that require multidimensional homonuclear correlation experiments involving nuclides with low natural abundance, ${ }^{25-29}$ as well as for the study of low gyromagnetic ratio ${ }^{30}$ quadrupolar nuclei. ${ }^{31-34}$ This original approach is the first step towards sustainable helium spinning and is fully compatible with the use of smaller diameter rotors for ultra-fast sample spinning.

\section{Experimental}

\section{DNP samples}

The cellulose sample was obtained by suspending cellulose in a solution of $20 \mathrm{mM}$ TOTAPOL, [D $\mathrm{D}_{8}$-glycerol, $\mathrm{D}_{2} \mathrm{O}$, and $\mathrm{H}_{2} \mathrm{O}$ $(60 / 30 / 10, \mathrm{v} / \mathrm{v} / \mathrm{v})$, which was then packed into a $3.2 \mathrm{~mm}$ outerdiameter zirconia rotor. To test DNP sensitivity, solutions of $2 \mathrm{M}$ ${ }^{13} \mathrm{C}$-urea in $\left[\mathrm{D}_{8}\right]$-glycerol, $\mathrm{D}_{2} \mathrm{O}$, and $\mathrm{H}_{2} \mathrm{O}(60 / 30 / 10, \mathrm{v} / \mathrm{v} / \mathrm{v})$ with different concentrations (given in the text) of the polarizing agents TOTAPOL ${ }^{35}$ and AMUPol $^{19}$ were used, and packed into $3.2 \mathrm{~mm}$ outer-diameter sapphire rotors. The $\gamma$-alumina sample was impregnated with a solution of $\left[\mathrm{D}_{6}\right]$-DMSO, $\mathrm{D}_{2} \mathrm{O}$, and $\mathrm{H}_{2} \mathrm{O}$ (78/14/8, w/w/w) containing $10 \mathrm{mM}$ AMUPol and packed into a $3.2 \mathrm{~mm}$ outer-diameter zirconia rotor. Nanotubes of the cyclic dipeptide cyclo-diphenylalanine were prepared using a MatrixFree approach ${ }^{25}$ so that TOTAPOL could be dispersed within the powdered sample, giving good sensitivity for MAS-DNP experiments.

\section{DNP experiments}

All DNP experiments were performed with a 9.4 T Bruker BioSpin solid-state DNP-NMR spectrometer, ${ }^{2}$ equipped with a 263 $\mathrm{GHz}$ gyrotron and a modified low-temperature triple-resonance MAS probe suitable for $3.2 \mathrm{~mm}$ outer-diameter rotors. To reach cryogenic temperatures, the probe was connected to the here presented closed-loop NUMOC system. The sample temperature was measured using a thermocouple placed near the rotor, with corrections according to measurements of the saturation-recovery buildup times of ${ }^{79} \mathrm{Br}$ in an external reference of $\mathrm{KBr}^{36}$

\section{Results and discussion}

\section{The cryostat}

Fig. 1 shows schematics for both the MAS stator and the device we have named NUMOC (NUclear magnetic resonance spinning MOdule Cryostat) that is used to cool He gas, which is subsequently sent to the stator in three separate lines to provide bearing gas (to cushion the rotor), drive gas (to spin the rotor), and cooling gas (to vary the sample temperature). Cold He gas then leaves the stator, is recovered and recycled through NUMOC in a closed-loop circuit to continue cooling and rotating the sample. The simultaneous cooling of all three lines of He gas to similar temperatures prevents temperature gradients across the sample, ensures easy recuperation of the gas, and permits fast sample spinning. Thus, combining NUMOC and a $3.2 \mathrm{~mm}$ MAS test stator only (i.e., without a full NMR probe) MAS rates of $5 \mathrm{kHz}$ at $10 \mathrm{~K}$ and $25 \mathrm{kHz}$ at $90 \mathrm{~K}$ were achieved.

The $\mathrm{He}_{\text {(liquid) }}$ consumption of NUMOC is 5 to $25 \mathrm{~L} \mathrm{~h}^{-1}$ depending on the desired sample temperature (30-90 K) and spinning frequency (up to $25 \mathrm{kHz}$ for a $3.2 \mathrm{~mm}$ rotor). Note that NUMOC can be used instead with $\mathrm{N}_{2 \text { (liquid) }}$ as the cryogen, with a consumption of approximately $10 \mathrm{~L} \mathrm{~h}^{-1}$, to achieve sample temperatures $>90 \mathrm{~K}$. As a comparison, the commercial system requires $10-20 \mathrm{~L} \mathrm{~h}^{-1}$ of $\mathrm{N}_{2 \text { (liquid) }}$ to reach a minimum sample temperature of approximately $100 \mathrm{~K}$ at maximum spinning frequencies of $15 \mathrm{kHz}$. The $\mathrm{He}_{(\mathrm{gas})}$ consumption of NUMOC is $\ll 1 \mathrm{~L} \mathrm{~h}^{-1}$ to compensate for leaks in the closed-loop $\mathrm{He}_{\text {(gas) }}$ circuit and for pneumatic insertion/ejection of the sample (c.f. $\gg 1000 \mathrm{~L} \mathrm{~h}^{-1}$ of $\mathrm{N}_{2 \text { (gas) }}$ for the commercial system, since there is no closed-loop). The low temperature operation with stable sample spinning $( \pm$ few $\mathrm{Hz}$ ) can be maintained as a function of the size of the $\mathrm{He}_{(\text {liquid) }}$ vessel connected to NUMOC. A $200 \mathrm{~L}$ tank of $\mathrm{He}_{\text {(liquid) }}$ will thus enable $\sim 10 \mathrm{~h}$ of stable operation. A fully autonomous system where the $\mathrm{He}_{(\text {liquid) }}$ consumption is zero thanks to the use of suitable cryo-coolers is currently under testing.

The Bruker Biospin ULT-MAS-DNP functional prototype probe is based on a similar design to the LT-MAS-DNP probe used for $100 \mathrm{~K}$ measurements. The probe was modified to

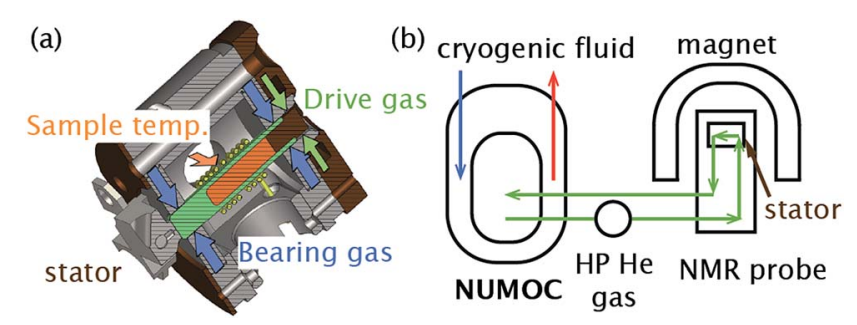

Fig. 1 Schematics of (a) an NMR stator and (b) the ultra-lowtemperature MAS-DNP setup called NUMOC. 
prevent any cold gas leakage and to allow spinning and cooling the rotors using a closed-loop circuit powered by a unique compressor. The nominal pressure of the cryostat was chosen to be higher than atmospheric pressure to prevent any air contamination that could result in ice formation and partial blockages in the system. The helium circuit was also connected to a high-pressure helium tank to ensure constant gas volume operation and compensate for any helium leaks if present. The rotor insert/eject system was also optimized to allow safe operation at cryogenic temperatures between $30 \mathrm{~K}$ and $100 \mathrm{~K}$.

\section{DNP results at fast MAS frequencies}

When combining NUMOC with the ULT-MAS-DNP probe and using liquid $\mathrm{N}_{2}$ as the cryogenic fluid to cool the He gas lines, sample temperatures similar to the commercial setup ( $\sim 90 \mathrm{~K})$ are obtained. However, as shown in Fig. 2, MAS is then not limited any more by the fluidic properties of $\mathrm{N}_{2}$ at $\sim 100 \mathrm{~K}$ (maximum MAS frequency of $15 \mathrm{kHz}$ for $3.2 \mathrm{~mm}$ rotors), and stable spinning frequencies up to $25 \mathrm{kHz} \pm 10 \mathrm{~Hz}$ can be easily achieved with $\mathrm{He}$ gas. This corresponds otherwise to the maximum spinning frequency specification of $3.2 \mathrm{~mm}$ probes at room temperature. For high-magnetic field ssNMR fast sample spinning is required to average chemical shift anisotropy (CSA) interactions, which are proportional to the external magnetic field strength. Moreover, faster sample spinning contributes to spectral linewidth narrowing, increasing thus signal-to-noise and resolution. This is especially true for ${ }^{1} \mathrm{H}$ resonances, which are usually broadened by strong homonuclear dipolar couplings, and for quadrupolar nuclei such as ${ }^{17} \mathrm{O},{ }^{27} \mathrm{Al}$, and ${ }^{43} \mathrm{Ca}$ that experience a broadening due to the second order quadrupolar interaction. Interestingly, the DNP enhancement, defined as the ratio of the returned signal intensities measured in the presence and absence of $\mu \mathrm{w}$ irradiation ( $\varepsilon_{\text {on/off }}$ ), is similar in this fast spinning regime $\left({ }^{1{ }^{H}} \varepsilon_{\text {on/off }} @ 25 \mathrm{kHz}=25\right)$ to that measured at a MAS frequency of $8 \mathrm{kHz}\left({ }^{1 \mathrm{H}} \varepsilon_{\text {on } / \text { off }} @ 8 \mathrm{kHz}=20\right)$.

\section{DNP results at temperatures $\ll 100 \mathrm{~K}$}

By changing the cryogenic $\mathrm{N}_{2}$ fluid used to cool the He gas lines to $\mathrm{He}$, much lower sample temperatures can be achieved with the described setup. Fig. 3a shows ${ }^{1} \mathrm{H}$ spectra recorded at $55 \mathrm{~K}$ on the model system of ${ }^{13} \mathrm{C}$-urea in a glass-forming matrix along with the binitroxide polarizing agent TOTAPOL ${ }^{35}(20 \mathrm{mM})$ that has been introduced for CE-DNP. At a MAS frequency of $10 \mathrm{kHz}$,

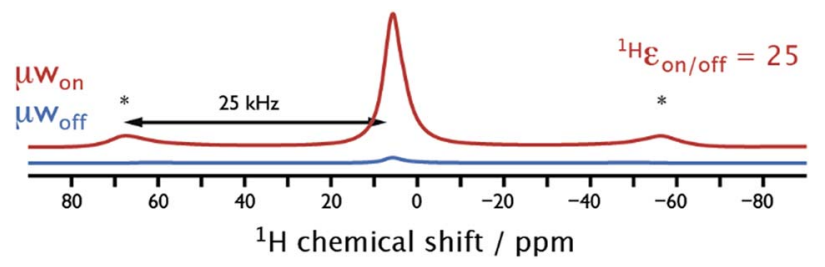

Fig. $2{ }^{1} \mathrm{H}$ Hahn-echo NMR spectra recorded with (red) and without (blue) $\mu \mathrm{w}$ irradiation suitable for CE-DNP on the cellulose sample. The experiments were performed with the setup shown in Fig. 1b with He gas to achieve a MAS frequency of $25 \mathrm{kHz}$ at a sample temperature of $90 \mathrm{~K}$. Asterisks denote spinning sidebands. reducing the sample temperature to $\sim 55 \mathrm{~K}$ leads to a DNP enhancement ${ }^{1 \mathrm{H}} \varepsilon_{\text {on/off }} @ 55 \mathrm{~K}=190$, which is three-fold higher than the enhancement obtained with standard conditions; at $110 \mathrm{~K},{ }^{1 \mathrm{H}} \varepsilon_{\text {on/off }} @ 110 \mathrm{~K}=60$. Using $\operatorname{AMUPol}^{19}(5 \mathrm{mM})$, a biradical specifically designed to optimize CE-DNP efficiency, enhancement of ${ }^{1 \mathrm{H}} \varepsilon_{\text {on/off }} @ 110 \mathrm{~K}=290$ is obtained for a similar sample of ${ }^{13} \mathrm{C}$-urea at $110 \mathrm{~K}$ (Fig. 3b). Fig. 3c shows that reducing the sample temperature leads to a strong increase of the DNP enhancement ${ }^{1 \mathrm{H}} \varepsilon_{\text {on/off. }}$ At $55 \mathrm{~K},{ }^{1 \mathrm{H}} \varepsilon_{\text {on/off }} @ 55 \mathrm{~K}=677 \pm 34$, as shown in Fig. 3b. This value can be surprising at first sight as it is close to the theoretical enhancement maximum, given by $\gamma_{\mathrm{e}} / \gamma_{1 \mathrm{H}}=658$. It is here important to note that the reported values of ${ }^{1 \mathrm{H}} \varepsilon_{\text {on/off }}$ do not account for nuclear depolarization, which results in a loss of nuclear magnetization at steady-state in absence of $\mu \mathrm{w}$ irradiation and under MAS when compared to Boltzmann equilibrium. ${ }^{37,38}$ This explains why ${ }^{1 \mathrm{H}_{1}} \varepsilon_{\text {on/off }}$ may exceed the theoretical enhancement maximum. To correct ${ }^{1 \mathrm{H}} \varepsilon_{\text {on/off }}$ towards the real enhancement gain taking into account depolarization would have required measurement of the static ${ }^{1} \mathrm{H}$ resonance. ${ }^{38}$ However, for static samples, it is difficult with our experimental setup to achieve long-term temperature stability, which would be required for a reliable estimation of the depolarization. Nevertheless, even without accounting for depolarization, it is evident that substantial gains in sensitivity can be obtained by DNP at reduced temperatures (vide infra).

Since sensitivity is defined as the signal-to-noise ratio per unit square root of time, $(\mathrm{S} / \mathrm{N})_{\sqrt{ } t}$, the rate at which the experiment can be repeated is crucial. Usually, this rate is limited by the nuclear spin-lattice relaxation time constants $\left(T_{1 \mathrm{n}}\right)$. One assumed drawback of lowering the sample temperature was the lengthening of these characteristic times that would be deleterious for the sensitivity. However, we observe experimentally in this study that the magnetization build-up times (after saturation), both in the presence and absence of $\mu \mathrm{w}$ irradiation, do not change significantly as the temperature is decreased below $100 \mathrm{~K}$ for samples that experience the CE. Using the model sample of ${ }^{13} \mathrm{C}$-urea, build-up time constants of $10.7 \mathrm{~s}$ (with $5 \mathrm{mM}$ AMUPol) and $3.0 \mathrm{~s}$ (with $12 \mathrm{mM}$ AMUPol) were recorded at $110 \mathrm{~K}$. When the sample temperature was lowered to $35 \mathrm{~K}$, build-up constants of $12.3 \mathrm{~s}$ (5 mM AMUPol) and $3.8 \mathrm{~s}(12 \mathrm{mM}$ AMUPol) were obtained, respectively. Interestingly, $T_{1 \mathrm{n}}$ is therefore not the limiting factor for the build-up rate, since in the absence of biradicals, ${ }^{1 \mathrm{H}_{1}} T_{1 \mathrm{n}}>60 \mathrm{~s}$ at $100 \mathrm{~K}$ for this sample. Furthermore, induced relaxation by the presence of the paramagnets is also not responsible for the build-up rates since this would induce large changes with temperature. ${ }^{39}$ The magnetization saturation-recovery build-up times must then be determined by both the $\mathrm{CE}$ and spin-diffusion, which respectively exchanges electron polarization difference with the nuclear spins and spreads hyperpolarization throughout the sample. Its theoretical dependence as a function of temperature is certainly complicated. In the experimental frame of this study, lowering the temperature here does not impact significantly on the optimum experimental repetition rate, and is therefore not prohibitive in terms of $(\mathrm{S} / \mathrm{N})_{\sqrt{ } t}$.

Fig. 3d depicts a further advantage of lowering the sample temperature. To obtain an efficient CE-DNP mechanism, 
(a)

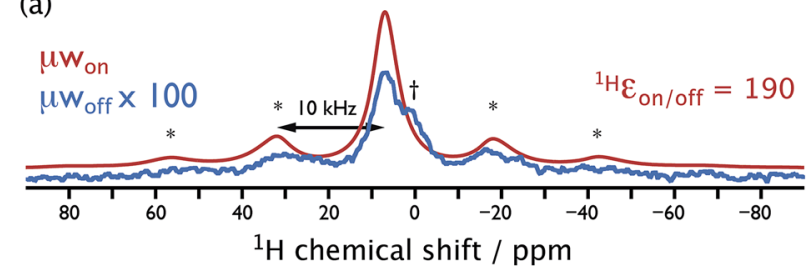

(b)

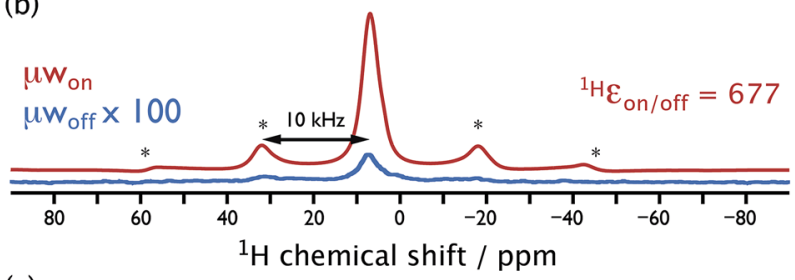

(c)

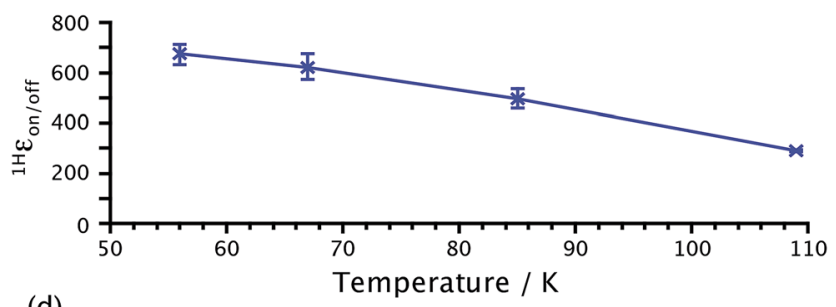

(d)

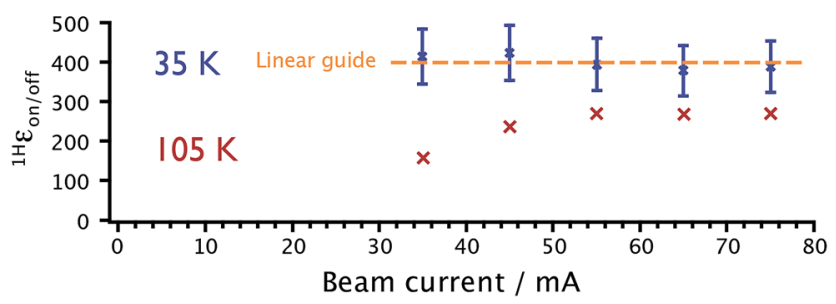

Fig. $3{ }^{1} \mathrm{H}$ Hahn-echo NMR spectra recorded with (red) and without (blue) $\mu \mathrm{w}$ irradiation suitable for CE-DNP on the ${ }^{13} \mathrm{C}$-urea model solution containing $20 \mathrm{mM}$ TOTAPOL (a) or $5 \mathrm{mM}$ AMUPol (b), at a sample temperature of $55 \mathrm{~K}$ and a MAS frequency of $10 \mathrm{kHz}$. The signals recorded in the absence of $\mu \mathrm{w}$ irradiation have been magnified by a factor of 100 for illustrative purposes. Asterisks and daggers denote spinning sideband and 'plug' signals, respectively. (c) The measured DNP-enhancement ratio as a function of sample temperature for the sample from (b). (d) The measured DNP-enhancement ratio as a function of the gyrotron beam current, which has been checked to be proportional to $\mu \mathrm{w}$ power, for ${ }^{13} \mathrm{C}$-urea model solution containing $12 \mathrm{mM} \mathrm{AMUPol}$, recorded at a MAS frequency of $5 \mathrm{kHz}$ and sample temperatures of $105 \mathrm{~K}$ (red) and $35 \mathrm{~K}$ (blue).

sufficient $\mu \mathrm{w}$ power must be used to create a large polarization difference between electron spins of the polarizing agent. The required power depends on the relaxation properties of the electronic spins $\left(T_{1 \mathrm{e}}\right.$ and $\left.T_{2 \mathrm{e}}\right)$. At lower temperature, nitroxide electron relaxation time constants are increased ${ }^{40}$ and less $\mu \mathrm{w}$ power is needed to saturate the spin transitions. At $105 \mathrm{~K}$, high $\mu \mathrm{w}$ power from the gyrotron (a few watts at the sample) is needed for maximum DNP enhancement, as shown in Fig. 3d. However, at $35 \mathrm{~K}$ the $\mu \mathrm{w}$ power can be reduced by more than half without a noticeable change in the DNP enhancement. Therefore, less expensive, more adaptable (broadband, pulsed etc.), lower-power alternative $\mu \mathrm{w}$ sources may be suitable for efficient CE-DNP at temperatures $\ll 100 \mathrm{~K}$, replacing the expensive, highpower, narrowband, and continuous-wave gyrotrons.

\section{DNP results on $\gamma$-alumina}

The sample of $\gamma$-alumina $\left(\mathrm{Al}_{2} \mathrm{O}_{3}\right)$, which we recently studied at $104 \mathrm{~K}$ with MAS-DNP using $\mathrm{N}_{2}$ for sample spinning at $\sim 14 \mathrm{kHz},{ }^{41}$ was selected to highlight the importance of faster sample spinning using cold He gas. The catalytic surface of this material of high industrial relevance can be studied by centraltransition (CT)-selective cross-polarization (CP) to ${ }^{27} \mathrm{Al}$ nuclei from surface protons ${ }^{41}$ In Fig. 4 a the ${ }^{27} \mathrm{Al}$ spectrum recorded using a MAS frequency of $21 \mathrm{kHz}$ is completely free from spinning sidebands and spectral distortions. This is essential for higher-field studies where these distortions worsen at limited spinning rates and prevent crucial spectral data fitting. Interestingly, the peaks in the ${ }^{27} \mathrm{Al}$ spectrum at $21 \mathrm{kHz}$ MAS are significantly broader than those of the corresponding spectrum acquired at $13 \mathrm{kHz}$ MAS. This is the result of a better excitation at high MAS frequencies of ${ }^{27} \mathrm{Al}$ nuclei with large quadrupolar coupling constants. This leads to the observation of ${ }^{27} \mathrm{Al}$ species that were previously "invisible" at lower spinning speeds, again highlighting the importance of rapid sample rotation.

Fig. $4 \mathrm{~b}$ and $\mathrm{c}$ highlight the gain in sensitivity obtained by performing MAS-DNP experiments at lower temperatures. While ${ }^{1 \mathrm{H}} \varepsilon_{\text {on/off }}$ has increased by a factor of 3.3 from 42 at $105 \mathrm{~K}$ to 140 at $36 \mathrm{~K}$, more importantly $(\mathrm{S} / \mathrm{N})_{\sqrt{ } t}$, which is the real measure of the sensitivity gain, has increased by a factor of 2.3, resulting in five-times faster experiments. This sensitivity gain is however less than the expected factor of $\sim 10$ resulting from the multiplicative increased contributions from the ${ }^{1 \mathrm{H}} \varepsilon_{\text {on/off }}$ ratio (factor of 3.3) and Boltzmann equilibrium polarization (factor of 2.9, ignoring changes in rf-circuit sensitivity). The difference most likely comes from the aforementioned nuclear depolarization, ${ }^{37}$ which increases at lower temperatures, leading to a stronger overestimation of ${ }^{1 \mathrm{H}} \varepsilon_{\text {on/off }}$ with respect to the real DNP gain over the nuclear Boltzmann polarization. Depolarization amounts can be crudely estimated from Fig. $4 \mathrm{~b}$ and c. In the absence of $\mu \mathrm{w}$ irradiation (blue spectra), the $\mathrm{S} / \mathrm{N}$ is approximately the same at both temperatures, even though the expected $\mathrm{S} / \mathrm{N}$ should be $\sim 3$ times greater for the about thrice colder sample, owing merely to the increased Boltzmann polarization. This indicates that the nuclear depolarization is approximately 3 times as large in the sample at $36 \mathrm{~K}$ compared to that at $105 \mathrm{~K}$. The biradical AMUPol may therefore not be optimal for this ULT-MAS-DNP regime and may be best suited for experiments at higher temperatures. Alternative polarizing agents, specifically designed for this temperature regime, are currently under investigation in our laboratory.

Experiments on $\gamma$-alumina give further evidence for the polarization build-ups being dominated by CE-DNP and not $T_{1 \mathrm{n}}$. For this sample preparation, ${ }^{27} \mathrm{Al}$ spins do not experience any (observed) direct hyperpolarization. The polarization buildup time constant for ${ }^{27} \mathrm{Al}$ nuclei after saturation changes from 5 $\mathrm{s}$ at $100 \mathrm{~K}$ to $18 \mathrm{~s}$ at $40 \mathrm{~K}$. However, ${ }^{1} \mathrm{H}$ nuclei, which do experience CE-DNP, display almost no change in their build-up time constants, with values of $3.5 \mathrm{~s}$ at $100 \mathrm{~K}$ and $4 \mathrm{~s}$ at $40 \mathrm{~K}$. Lowering the temperature in the presence of the CE mechanism has only negligible effect on the polarization build-up times, and does not therefore induce any loss of sensitivity. 
(a)

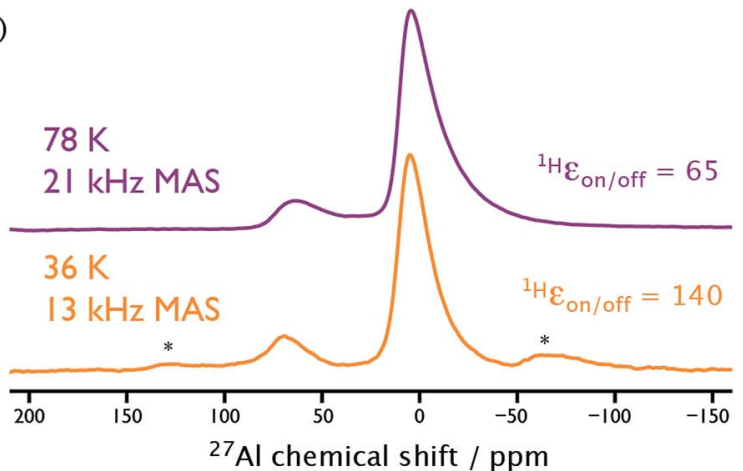

(b)

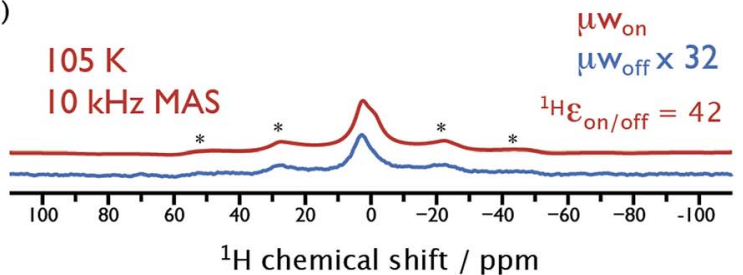

(c)

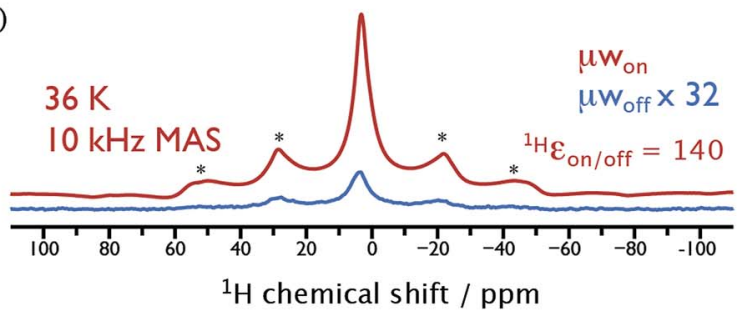

Fig. 4 NMR spectra recorded on the $\gamma$-alumina sample. (a) $\left\{{ }^{1} \mathrm{H}-\right\}^{27} \mathrm{Al}$ CT-CP spectra recorded at sample temperatures of $\sim 78 \mathrm{~K}$ (top, purple) and $\sim 36 \mathrm{~K}$ (bottom, orange) using MAS frequencies of $21 \mathrm{kHz}$ and $13 \mathrm{kHz}$, respectively. (b) ${ }^{1} \mathrm{H}$ Hahn-echo spectra recorded at a sample temperature of $\sim 105 \mathrm{~K}$ and a MAS frequency of $10 \mathrm{kHz}$ with (red) and without (blue) $\mu \mathrm{w}$ irradiation suitable for CE-DNP. (c) The same as for (b) at the same intensity scaling, but at a sample temperature of $\sim 36 \mathrm{~K}$. The signals in (b) and (c) recorded in the absence of $\mu \mathrm{w}$ irradiation have been magnified by a factor of 32 for illustrative purposes. Asterisks denote spinning sideband signals.

\section{DNP results on cyclo-FF}

Cyclo-diphenylalanine (cyclo-FF; shown in Fig. 5) can be prepared so as to self-assemble into semiconducting nanotubes. A special sample preparation procedure, which uses the TOTAPOL biradical, makes these nanotubes suitable for analysis by MAS-DNP. ${ }^{25}$ Fig. 5 shows the gain in $(\mathrm{S} / \mathrm{N})_{\sqrt{ } t}$ when performing DNP-enhanced experiments on this sample at $\sim 50 \mathrm{~K}$ compared to $\sim 110 \mathrm{~K}$. Already at $\sim 110 \mathrm{~K}$, MAS-DNP experiments gave $(\mathrm{S} / \mathrm{N})_{\sqrt{ } t}$ values that were 2 orders of magnitude larger than conventional ssNMR under ambient conditions. ${ }^{25}$ Here, lowering the sample temperature to $\sim 50 \mathrm{~K}$ results in 5.6 times further $(\mathrm{S} / \mathrm{N})_{\sqrt{ } t}$ increase, corresponding to an experimental timesaving of 6 orders of magnitude compared to conventional ssNMR. Again, using He gas for the sample spinning permitted spectra to be recorded at higher MAS frequencies than were previously possible at $100 \mathrm{~K}$ using $\mathrm{N}_{2}$ gas (see Fig. 5).

Unlike the sample of $\gamma$-alumina, which was studied by MASDNP using the AMUPol biradical (vide supra), the TOTAPOL

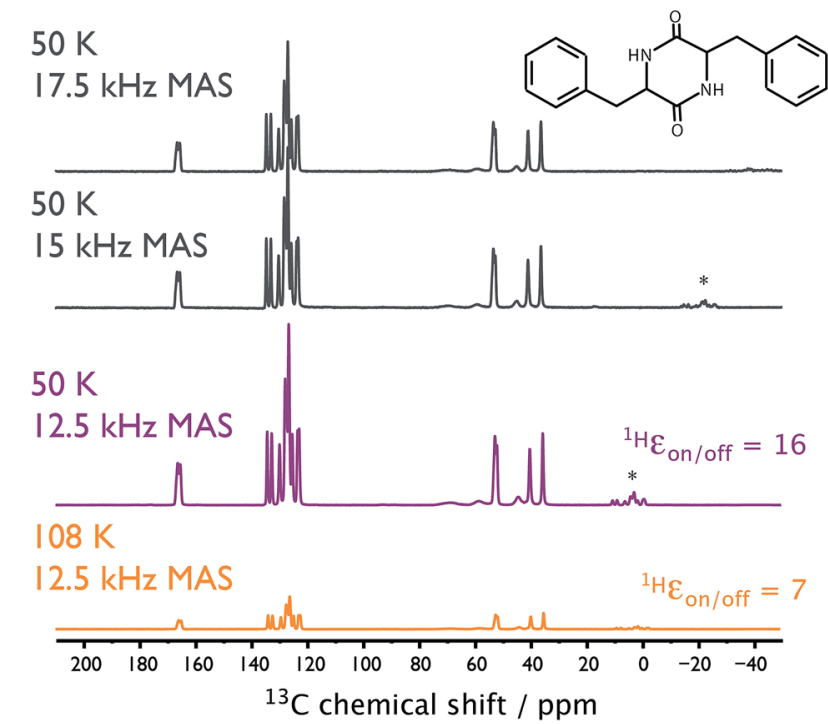

Fig. 5 NMR spectra recorded on the cyclo-FF (top right) sample. DNP-enhanced $\left\{{ }^{1} \mathrm{H}-\right\}^{13} \mathrm{C} \mathrm{CP}$ spectra recorded at sample temperatures of $\sim 108 \mathrm{~K}$ (orange) and $\sim 50 \mathrm{~K}$ (purple) using MAS frequencies of $12.5 \mathrm{kHz}$. Also shown (gray) are similar spectra recorded at $\sim 50 \mathrm{~K}$ using various MAS frequencies. $100 \mathrm{kHz}$ of SPINAL-64 decoupling ${ }^{42}$ was used for the $30 \mathrm{~ms}$ of acquisition without any evidence of arcing. The spectra have been scaled relative to their $(\mathrm{S} / \mathrm{N})_{\sqrt{ } \mathrm{t}}$. Asterisks denote spinning sideband signals.

biradical employed for the cyclo-FF sample shows no evidence of causing further depolarization at $50 \mathrm{~K}$ compared to $110 \mathrm{~K}$. It should also be noted that the polarization build-ups under these CE-DNP conditions were 3 and $4 \mathrm{~s}$ at 108 and $50 \mathrm{~K}$, respectively.

For this last tested sample it was necessary to utilize highpower heteronuclear decoupling to produce the thin peaks seen in Fig. 5, owing to the strongly coupled protons in the analyte. As stated above, there is a risk of electric arcing when using rf irradiation in a He gas environment. However, when applying the required long duration of high-power decoupling, no evidence of arcing was observed. This shows that sample spinning using a closed-loop cold He gas supply produced through NUMOC is fully compatible with state-of-the-art DNP-enhanced ssNMR. Moreover, it allows for faster sample spinning and experiments with much increased sensitivity.

\section{Conclusions}

To summarize, we have demonstrated here that orders of magnitude of additional time-savings can be achieved by performing MAS-DNP experiments at temperatures much lower than $100 \mathrm{~K}$. To achieve these results, we developed a cryostat that allows sustainable fast MAS using recycled cold helium gas. Firstly, sample spinning with helium gas permits much higher MAS frequencies than with conventional nitrogen gas, facilitating complex solid-state NMR measurements. Secondly, the potential drawback of decreasing the temperature, namely the increase in experimental repetition delays due to longer nuclear relaxation times, is bypassed by the use of CE-DNP. With this 
mechanism, the nuclear (hyper)polarization is built-up via $\mathrm{CE}$ and diffusion-type processes, which are shown to be quite insensitive to the temperature in the considered range. Finally, this approach leads to larger hyperpolarization and, more importantly, higher absolute sensitivity. It was demonstrated here at $10 \mathrm{~T}$ with $3.2 \mathrm{~mm}$ rotors, but it is fully compatible with even faster spinning and higher magnetic fields. Therefore, this approach will pave the way to the successful extension of MASDNP experiments to these higher fields as well as to envision the use of lower power and less expensive microwave sources, making the technique accessible to a wider community. This will open up possibilities for more comprehensive future biological, chemical, and physical studies.

\section{Acknowledgements}

This work was supported by the ANR (ANR08-CEXC-003-01 and ANR-08-BLAN-0306-02), the labex ARCANE (ANR-11-LABX-000301), and funding from the RTB. G.D.P. was supported by EU Marie Curie (PIEF-GA-2009-237646) for part of the work. Dr M. Giffard is acknowledged for the synthesis of the TOTAPOL biradical. The work on NUMOC could not have been completed as efficiently without the technical aid of Jean-Luc Le Bail, Louis Bizel-Bizzelot, Pierre Dalban-Moreynas, Thierry Jourdan, JeanMarc Mathonnet, Alexis Ponchon, and Bertrand Rollet, along with the institutional support of Pascale Maldavi, Thierry Douki, Alain Girard, and Lionel Duband. They are thanked enormously.

\section{References}

1 G. J. Gerfen, L. R. Becerra, D. A. Hall, R. G. Griffin, R. J. Temkin and D. J. Singel, J. Chem. Phys., 1995, 102, 9494-9497.

2 M. Rosay, L. Tometich, S. Pawsey, R. Bader, R. Schauwecker, M. Blank, P. M. Borchard, S. R. Cauffman, K. L. Felch, R. T. Weber, R. J. Temkin, R. G. Griffin and W. E. Maas, Phys. Chem. Chem. Phys., 2010, 12, 5850-5860.

3 A. B. Barnes, G. De Paëpe, P. C. A. van der Wel, K.-N. Hu, C.-G. Joo, V. S. Bajaj, M. L. Mak-Jurkauskas, J. R. Sirigiri, J. Herzfeld, R. J. Temkin and R. G. Griffin, Appl. Magn. Reson., 2008, 34, 237-263.

4 Q. Z. Ni, E. Daviso, T. V Can, E. Markhasin, S. K. Jawla, T. M. Swager, R. J. Temkin, J. Herzfeld and R. G. Griffin, Acc. Chem. Res., 2013, 46, 1933-1941.

5 A. J. Rossini, A. Zagdoun, M. Lelli, A. Lesage, C. Copéret and L. Emsley, Acc. Chem. Res., 2013, 46, 1942-1951.

6 D. Lee, S. Hediger and G. De Paëpe, Solid State Nucl. Magn. Reson., 2015, 66-67, 6-20.

7 W. H. Potter, Rev. Sci. Instrum., 1971, 42, 618.

8 V. Macho, R. Kendrick and C. Yannoni, J. Magn. Reson., 1983, 52, 450-456.

9 A. Hackmann, H. Seidel, R. Kendrick, P. Myhre and C. Yannoni, J. Magn. Reson., 1988, 79, 148-153.

10 C. S. Yannoni, P. C. Myhre and G. G. Webb, J. Am. Chem. Soc., 1990, 112, 8991-8992.
11 M. Carravetta, O. G. Johannessen, M. H. Levitt, I. Heinmaa, R. Stern, A. Samoson, A. J. Horsewill, Y. Murata and K. Komatsu, J. Chem. Phys., 2006, 124, 104507.

12 Y. Matsuki, K. Ueda, T. Idehara, R. Ikeda, I. Ogawa, S. Nakamura, M. Toda, T. Anai and T. Fujiwara, J. Magn. Reson., 2012, 225, 1-9.

13 M. Concistrè, O. G. Johannessen, E. Carignani, M. Geppi and M. H. Levitt, Acc. Chem. Res., 2013, 46, 1914-1922.

14 A. Samoson, T. Tuherm, J. Past, A. Reinhold, T. Anupõld and I. Heinmaa, Top. Curr. Chem., 2004, 246, 15-31.

15 K. R. Thurber and R. Tycko, J. Magn. Reson., 2008, 195, 179186.

16 R. Tycko, Acc. Chem. Res., 2013, 46, 1923-1932.

17 F. Mentink-Vigier, Ü. Akbey, Y. Hovav, S. Vega, H. Oschkinat and A. Feintuch, J. Magn. Reson., 2012, 224, 13-21.

18 K. R. Thurber and R. Tycko, J. Chem. Phys., 2012, 137, 084508.

19 C. Sauvée, M. Rosay, G. Casano, F. Aussenac, R. T. Weber, O. Ouari and P. Tordo, Angew. Chem., Int. Ed., 2013, 52, 10858-10861.

20 A. Zagdoun, G. Casano, O. Ouari, M. Schwarzwälder, A. J. Rossini, F. Aussenac, M. Yulikov, G. Jeschke, C. Copéret, A. Lesage, P. Tordo and L. Emsley, J. Am. Chem. Soc., 2013, 135, 12790-12797.

21 G. Mathies, M. A. Caporini, V. K. Michaelis, Y. Liu, K.-N. Hu, D. Mance, J. L. Zweier, M. Rosay, M. Baldus and R. G. Griffin, Angew. Chem., Int. Ed., 2015, DOI: 10.1002/anie.201504292.

22 B. Corzilius, A. a. Smith and R. G. Griffin, J. Chem. Phys., 2012, 137, 054201.

23 B. Corzilius, A. A. Smith, A. B. Barnes, C. Luchinat, I. Bertini and R. G. Griffin, J. Am. Chem. Soc., 2011, 133, 5648-5651.

24 J. Riikonen, S. Rigolet, C. Marichal, F. Aussenac, J. Lalevée, F. Morlet-Savary, P. Fioux, C. Dietlin, M. Bonne, B. Lebeau and V.-P. Lehto, J. Phys. Chem. C, 2015, 119, 19272-19278.

25 H. Takahashi, B. Viverge, D. Lee, P. Rannou and G. De Paëpe, Angew. Chem., Int. Ed., 2013, 52, 6979-6982.

26 H. Takahashi, S. Hediger and G. De Paëpe, Chem. Commun., 2013, 49, 9479-9481.

27 D. Lee, G. Monin, N. T. Duong, I. Zamanillo Lopez, M. Bardet, V. Mareau, L. Gonon and G. De Paëpe, J. Am. Chem. Soc., 2014, 136, 13781-13788.

28 G. Mollica, M. Dekhil, F. Ziarelli, P. Thureau and S. Viel, Angew. Chem., Int. Ed., 2015, 127, 6126-6129.

29 A. J. Rossini, A. Zagdoun, F. Hegner, M. Schwarzwälder, D. Gajan, C. Copéret, A. Lesage and L. Emsley, J. Am. Chem. Soc., 2012, 134, 16899-16908.

30 F. Blanc, L. Sperrin, D. Lee, R. Dervişoğlu, Y. Yamazaki, S. M. Haile, G. De Paëpe and C. P. Grey, J. Phys. Chem. Lett., 2014, 5, 2431-2436.

31 V. Vitzthum, P. Miéville, D. Carnevale, M. A. Caporini, D. Gajan, C. Copéret, M. Lelli, A. Zagdoun, A. J. Rossini, A. Lesage, L. Emsley and G. Bodenhausen, Chem. Commun., 2012, 48, 1988-1990.

32 D. Lee, H. Takahashi, A. S. L. Thankamony, J.-P. Dacquin, M. Bardet, O. Lafon and G. De Paëpe, J. Am. Chem. Soc., 2012, 134, 18491-18494. 
33 F. Blanc, L. Sperrin, D. A. Jefferson, S. Pawsey, M. Rosay and C. P. Grey, J. Am. Chem. Soc., 2013, 135, 2975-2978.

34 V. K. Michaelis, B. Corzilius, A. A. Smith and R. G. Griffin, J. Phys. Chem. B, 2013, 117, 14894-14906.

35 C. Song, K.-N. Hu, C.-G. Joo, T. M. Swager and R. G. Griffin, J. Am. Chem. Soc., 2006, 128, 11385-11390.

36 K. R. Thurber and R. Tycko, J. Magn. Reson., 2009, 196, 84-87.

37 K. R. Thurber and R. Tycko, J. Chem. Phys., 2014, 140, 184201.

38 F. Mentink-Vigier, S. Paul, D. Lee, A. Feintuch, S. Hediger, S. Vega and G. De Paëpe, Phys. Chem. Chem. Phys., 2015, 17, 21824-21836.
39 D. T. Peat, A. J. Horsewill, W. Köckenberger, A. J. Perez Linde, D. G. Gadian and J. R. Owers-Bradley, Phys. Chem. Chem. Phys., 2013, 15, 7586-7591.

40 H. Sato, S. E. Bottle, J. P. Blinco, A. S. Micallef, G. R. Eaton and S. S. Eaton, J. Magn. Reson., 2008, 191, 66-77.

41 D. Lee, N. T. Duong, O. Lafon and G. De Paëpe, J. Phys. Chem. C, 2014, 118, 25065-25076.

42 B. M. Fung, A. K. Khitrin and K. Ermolaev, J. Magn. Reson., 2000, 142, 97-101. 